\title{
Estrategias pedagógico-didácticas que coadyuvan a potenciar la comprensión y producción oral del inglés
}

\section{Pedagogical-didactic strategies that help boost listening comprehension and production of English}

\author{
Jorge Wilson Torres Hernández \\ Doctorando Universidad de las Américas y el Caribe UNAC, México \\ Correo electrónico: inglesbucaramanga@hotmail.com \\ María Cristina Gamboa Mora \\ Doctora en Innovación e Investigación en Didáctica Docente \\ Universidad Nacional Abierta y a Distancia, UNAD \\ Bogotá, Colombia \\ Correo electrónico: maria.gamboa@unad.edu.co
}

Recibido: 30 de mayo de 2018

Aceptado: 12 de julio de 2018

\section{Cómo citar este artículo:}

Torres, J.W., y Gamboa, M.C. (2019). Estrategias pedagógico-didácticas que coadyuvan a potenciar la comprensión y producción oral del inglés. Espiral, Revista de Docencia e Investigación, 9(1), 29 - 49.

\section{Resumen}

El artículo de investigación busca establecer la efectividad de la creación de un ambiente intencionado para el aprendizaje del idioma extranjero con el fin de contrarrestar el enfoque pasivo de comprensión y producción oral en inglés de los estudiantes en las comunas 1 y 2 de Bucaramanga, Colombia; posibilitando la inclusión desde el currículo mediante la estimulación multicanales y la implementación de estrategias para el aprendizaje significativo. El diseño cuantitativo de la investigación se configuró definiendo dos grupos: control y experimental con estudiantes de una institución que atiende población en situación de vulnerabilidad. En el experimento se realizó un análisis Manova con los resultados de un pretest y un postest de evaluación de las habilidades de escuchar y hablar, estableciendo correlaciones con los canales de percepción caracterizados para cada uno de los estudiantes en los dos grupos. Se obtuvieron diferencias estadísticamente significativas (Traza Pillai $p<0,05)$ para la variable habilidad lingüística escuchar entre el grupo control y el grupo experimental, siendo superiores en este último. Hubo tendencia a mostrar diferencias significativas en la habilidad lingüística hablar $(p=0.062)$. Las estrategias efectivas son las que fomentan la interacción, el lenguaje en contexto, el aprendizaje colaborativo, input comprensible, la reducción de la ansiedad de los estudiantes, su participación autodirigida.

Palabras clave: Estrategia, habilidad lingüística, inglés, canal de percepción, aprendizaje.

\section{Abstract}

This article seeks to establish the effectiveness of the implementation of an intended environment for foreign language learning in order to diminish the passive approach of listening and speaking skills of students in communes 1 and 2 of Bucaramanga-Colombia, supporting inclusion from the curriculum; through multichannel stimulation and the implementation of strategies for meaningful learning. The quantitative research design was configured by setting two groups: a control group and an experimental one with students from an educational institution that assists students in vulnerable situations. For the experiment, a Manova analysis was performed taking into consideration the results of a pretest and a post test for listening and speaking skills, establishing correlations with the perception channels characterized for each of the students in both groups. Significant difference were achieved (Traza Pillai $p<0,05$ ) for the variable listening skill between the control group and the experimental group, getting higher the last one. There was a tendency to show significant differences in linguistic ability to speak ( $p=$ 0.062). Effective strategies are the ones that encourage interaction, language in context, collaborative learning, comprehensible input, the reduction of students' anxiety as well as their active and self-directed participation.

Keywords: Strategy, linguistic skills, English, perception channel, learning. 


\section{Introducción}

El artículo de investigación presenta los resultados de una intervención didáctica que consistió en la implementación de un experimento diseñado para articular actividades de aprendizaje de lengua extranjera, dirigidas a la estimulación de los canales de percepción de los estudiantes con el uso de estrategias que fortalecen la producción y comprensión oral en inglés de los estudiantes en las comunas 1 y 2 de Bucaramanga, Colombia.

La propuesta se origina debido a la necesidad de proporcionar una educación de calidad a los niños, niñas y jóvenes en condiciones de vulnerabilidad de estas dos comunas. En este sentido, cabe subrayar que la inclusión educativa puede verse desde diferentes aristas, es inherente al principio de educación para todos, por tanto, requiere de un cambio cultural sobre cómo concebir y desarrollar la educación en sus aspectos curriculares, como en la actitud de los maestros frente a los estudiantes. La diversidad en las aulas convoca a la implementación de estrategias para el proceso de enseñanzaaprendizaje, que está mediado en las instituciones por el currículo en favor de experiencias exitosas y gratificantes (Ministerio de Educación del Ecuador, 2011). Por consiguiente, la inclusión como oportunidad de desarrollo para todos, debe plantearse desde un currículo de calidad y pertinencia.

De ahí, la implementación de actividades pertinentes dirigidas a mejorar las dos habilidades lingüísticas orales de la lengua inglesa, en coherencia con lo establecido en el Programa Nacional de Bilingüismo (PNB), formulado por el Ministerio de Educación Nacional - MEN, apoyado por el Consejo Británico (2004) con la meta de "lograr ciudadanos y ciudadanas capaces de comunicarse en inglés, de tal forma que se puedan insertar al país en los procesos de comunicación universal, en la economía global y en la apertura cultural, con estándares internacionalmente comparables" (MEN, 2006, p. 6).
En este sentido, Herazo, Jerez, y Lorduy (2012) destacan que el propósito general del PNB radica en el desarrollo de la proficiencia funcional de la lengua inglesa en los niveles del sistema educativo colombiano. Específicamente, en los niveles de primaria y bachillerato, pretende fortalecer el proceso de enseñanzaaprendizaje y se planteó como meta que para el año 2025, el 50\% de los estudiantes de último grado de bachillerato logren el nivel B1 en los resultados del componente de inglés propuestos en la prueba Saber $11^{\circ}$. Para ello, el PNB trazó tres pilares estratégicos: 1. preparación de docentes en sus competencias comunicativas, 2. acompañamiento a las secretarías de Educación para la realización de capacitaciones en las metodologías actuales de enseñanza de lengua inglesa, y 3. creación del material didáctico English Please! para los estudiantes de media secundaria en el 2012.

La transformación en el proceso de enseñanza-aprendizaje de la lengua extranjera se empieza a evidenciar desde la puesta en práctica del PNB; sin embargo, el MEN consideró que los alcances hasta entonces no eran los pretendidos, según los resultados de la prueba Saber $11^{\circ}$. Esto se explica dado que los resultados del componente eran muy bajos en cuanto a los objetivos, un $51 \%$ de los alumnos tienen un nivel $-A 1$, un $35 \%$ se encuentra en $A 1$, un $7 \%$ se encuentra en $A 2$ y tan solo un $7 \%$ se encuentra en B1 y B+ (ICFES, 2016).

Por consiguiente, el MEN se vio en la necesidad de consolidar una propuesta metodológica que coadyuve al alcance de los objetivos pretendidos del PNB, la cual ofreciera oportunidades de aprendizajes para todos los alumnos en el territorio nacional. Como resultado, se constituyó el currículo sugerido para la enseñanza de lenguas, donde el MEN (2016) introduce los Derechos Básicos de Competencias en L2, en concordancia con los Estándares Básicos de Competencias en lenguas extranjeras. En esta misma línea de ideas, se creó un material didáctico llamado Way to go para trabajarse en 
los grados $6^{\circ}, 7^{\circ}$ y $8^{\circ}$, el que fue elaborado para adaptarse a las necesidades particulares de las instituciones. Cabe destacar que el referido material tan solo es trabajado por algunos colegios estatales que hacen parte de las denominadas instituciones educativas (IE) focalizadas. En la figura 1 se manifiestan los logros alcanzados en el 2017, y las metas pretendidas en 2018 en los tres pilares estructurales del PNB:

\section{Figura 1. Alcances y metas pretendidas del PNB}

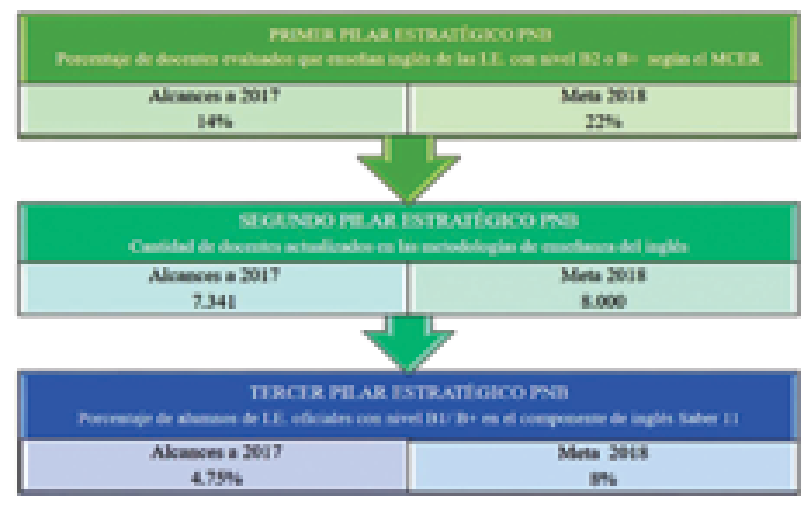

Fuente: MEN, 2019.

Como se puede observar, luego de poner en marcha las nuevas estrategias del PNB los estudiantes que alcanzaron el nivel B1 y B+en el área de inglés en la Prueba Saber 11 son tan solo el $4.75 \%$ (ICFES, 2018). Los datos reflejan que no han sido significativos los alcances en cuanto a la meta del dominio del inglés en Colombia, el panorama es aún más desalentador, puesto que tan solo quedan 7 años para lograr que la mitad de los estudiantes de Bachillerato alcancen el nivel B1 o B+ de acuerdo con el Marco Común Europeo de Referencia para la enseñanza de las lenguas (MCER), lo que significa que el país ha logrado el bilingüismo.

Es imperioso señalar que el componente de inglés de la prueba Saber $11^{\circ}$ propende que el estudiante demuestre sus habilidades comunicativas exclusivamente a nivel de lectura y uso del lenguaje, es decir, esta prueba tan solo evalúa una de las cuatro habilidades lingüísticas de L2, por ende, no toma en consideración las habilidades de producción y comprensión oral. Ahora bien, pese a que no se encuentra una justificación definida para no llevar a cabo una evaluación más integral que involucre las cuatro habilidades, se podría deducir que este hecho se debe a inconvenientes relacionados con la cantidad de tiempo para efectuar la prueba de producción oral, al igual que la erogación de los recursos técnicos y humanos requeridos para la valoración del desempeño de las demás destrezas. Este es uno de los mayores retos que debe afrontar el Instituto Colombiano para el Fomento de la Educación Superior - ICFES en el diseño del componente de lengua extranjera, puesto que la validez de una prueba de calidad, que mida el desarrollo de la competencia comunicativa en inglés debe estar alienada con cada destreza lingüística involucrada en ella.

En este aspecto, López, Ropero y Peralta (2011) enfatizan que la versión actual del componente de la prueba de inglés propuesta en el examen Saber $11^{\circ}$ no es válida para establecer los niveles del MCER, lo que indica que tampoco provee información acerca de las habilidades lingüísticas en $L 2$ de los discentes de último nivel de bachillerato del país (p. 12). Contradictoriamente, los estándares básicos de competencias en lengua extranjera propuestos por el MEN (2016) enfatizan que la producción oral y la comprensión oral son de gran importancia para lograr el dominio en un idioma extranjero, al igual que las habilidades de comprensión y producción escrita.

Teniendo en cuenta lo anterior, y con aras de integrar el desarrollo de estas dos habilidades al proceso de enseñanza-aprendizaje se llevó a cabo una revisión documental de las estrategias que pueden ser utilizadas para potenciar la producción y comprensión de los estudiantes que asisten a las IE de las comunas 1 y 2. Para posteriormente, incluirlas en el ambiente intencionado que se convirtió en el experimento para establecer la efectividad de las estrategias que incorporan la estimulación de los canales de percepción. 


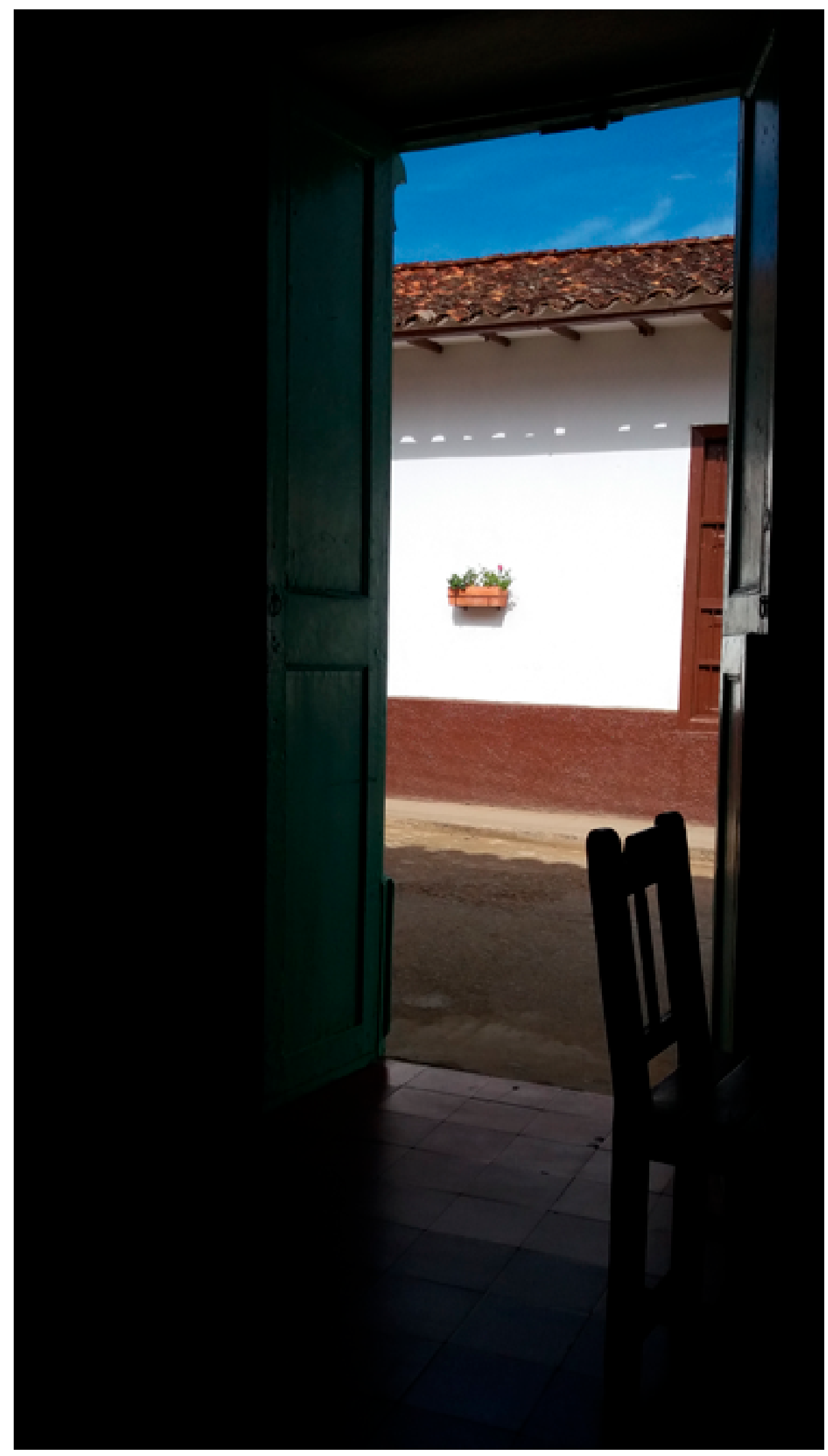




\section{La producción y la comprensión oral: estrategias para mejorar su adquisición}

Desde un enfoque comunicativo, las destrezas "auditiva" y"oral" están relacionadas (Serrón, 2001). La adquisición de la habilidad de producción oral es un proceso progresivo y dirigido, en el cual, el alumno practica el idioma de forma real a través de discusiones, conversaciones u otras estrategias que lo motiven a expresarse en el idioma de estudio. El enfoque comunicativo ha puesto la habilidad oral como el pilar más importante en el proceso de enseñanza-aprendizaje de un idioma extranjero, con el principal objetivo de comunicarse lo mejor posible con personas que hablen el idioma extranjero. No obstante, la adquisición de esta habilidad es ardua y demandante, por esta razón, muchos alumnos se sienten desmotivados después de algún tiempo de estudiar el idioma.

En efecto, hablar en inglés es una cuestión compleja para los aprendices de lengua extranjera, ya que lograr una comunicación efectiva requiere la habilidad de utilizar la lengua apropiadamente por medio de la interacción social. De acuerdo con los estándares básicos de competencias en lengua extranjera del MEN (2016) la producción oral es de gran importancia para comunicarse, al igual que la lengua materna. Empero, no se trabaja lo suficiente y como consecuencia, los graduados en la mayoría de instituciones públicas colombianas no desarrollan su habilidad oral apropiadamente, aún más, aquellos que tienen puntajes altos en exámenes escritos se les dificulta expresarse de forma oral en la lengua de estudio. Una de las posibles causas de este hecho radica en la percepción por los docentes de la importancia de esta habilidad. En este sentido, Goh y Burns (2012) manifiestan que los docentes de segunda lengua reconocen que la producción oral es una de las habilidades más importantes, igualmente que debe ser desarrollada por sus alumnos; sin embargo, algunos no son conscientes de en qué forma las actividades deben ser planeadas para brindar la posibilidad de tener éxito en su desa- rrollo, pues muchas de las estrategias empleadas en clase no involucran a los estudiantes en actividades para ejercitar la producción oral.

En esta misma línea de ideas, según Chastain (1998) la habilidad de producción oral requiere muchos componentes, ya que su desarrollo va más allá de pronunciar correctamente los sonidos, elegir las palabras adecuadas o realizar una correcta construcción gramatical, requiere asimismo, una amplia variedad de habilidades y conocimientos culturales y sociales, igualmente, la interacción con sus demás compañeros es de vital importancia para desarrollar esta habilidad. Por esta razón, los docentes de idioma extranjero afrontan el problema al momento de preparar a sus estudiantes para utilizar la lengua en esta habilidad específica. La manera de realizar esta preparación y efectividad depende en gran medida de las perspectivas que tienen los docentes sobre los objetivos de la actividad. Es así como, durante la planeación de las actividades se deben tener en cuenta qué clase de vocabulario y qué aspectos gramaticales deben trabajarse, e igualmente de qué manera serán presentados para que sean entendidos claramente por los estudiantes. Bygate (1987) manifiesta que "los hablantes de una lengua extranjera utilizan sus experiencias y conocimiento lingüístico para crear un mensaje que debe ser significativo para la audiencia (p. 3)".

Para Goh y Burns, "la producción oral es una habilidad altamente compleja y dinámica que requiere el uso de varios procesos simultáneos, cognitivos físicos y socio culturales" (2012, p. 152). Igualmente, los conocimientos y las habilidades tienen que ser activadas de forma rápida en tiempo real. De ahí, los estudiantes estarán involucrados en actividades significativas en donde pueden hacer uso de la lengua, entender, interpretar su realidad y construir nuevo conocimiento $y$, por tanto, desarrollar sus competencias comunicativas. 
Aunado a lo anterior, Fink (2003) resalta la importancia de inspirar a los estudiantes a que hagan conexiones entre el conocimiento recibido durante sus clases y sus vidas, de tal forma que esta información pueda ser empleada en nuevas situaciones. No obstante, los estudiantes a menudo tienen una actitud reacia a participar en las actividades orales, ya que no perciben la relevancia entre el tema y las actividades que desarrollan en sus vidas diarias. Ahora bien, Hedge (2002) indica que el elemento con mayor importancia en la competencia oral es identificar las diferentes clases de situaciones en las cuales se produce la lengua, después los aprendices pueden comunicar sus propias ideas, opiniones, creencias o gustos, por tal razón es imprescindible que conozcan expresiones y vocabulario que se utilice con este propósito. Asimismo, la función social de la lengua es un aspecto crucial que se debe tener en cuenta; por ello, la necesidad de que los docentes conceptualicen las actividades orales para que los estudiantes se involucren y usen el inglés para propósitos reales y significativos.

Desde un punto de vista cognitivo, Levelt (1995) considera que los estudiantes deben prepararse conceptualmente para lo que van a decir, formular sus exposiciones para expresar sus ideas y articularlos de tal forma que sean comprensibles por los demás. La preparación conceptual abarca la selección del tema o la información, la cual dependerá del conocimiento previo del hablante, del conocimiento global y de lo que puede recuperar por medio de la memoria a largo plazo. En pequeños discursos, los estudiantes deben tener acceso a las respuestas que sean relevantes y apropiadas para la conversación en curso. De esta forma, las ideas deben ser formuladas, y puestas en esquemas concatenados de la gramática y el vocabulario específico para que los alumnos puedan tener acceso a ellas. Por último, los hablantes deben conocer y tener control de los sonidos, y la entonación de la lengua en estudio para que los oyentes puedan entender el mensaje.
Estos procesos presentan retos considerables para los aprendices de idioma extranjero. En primer lugar, porque no tienen el suficiente conocimiento del tema o las estructuras del discurso que caracterizan el habla con relación al tema. Para este caso, es necesario que los docentes tengan en consideración las necesidades de los aprendices y determinar el tiempo necesario para su preparación y ampliación de su conocimiento, antes que pedirles que lleven a cabo una tarea de producción oral. En segundo lugar, los estudiantes necesitan tener acceso a la gramática, el vocabulario y las características del discurso que les permita hablar sobre el tema. Es muy importante que se les brinde la posibilidad de practicar estas características mencionadas, particularmente de aquellas que estructuran patrones del texto hablado (por ejemplo, oraciones, palabras familiares, marcadores discursivos), antes de realizar el ejercicio de la producción oral.

Igualmente, se requiere prestar atención a la habilidad de los estudiantes para pronunciar las palabras y las expresiones que necesitan para hablar; no obstante, esta área poco se trabaja en la enseñanza de la producción oral. Asimismo, Burns y Seidlhofer (2010) sugieren que "los docentes deben presentar a sus alumnos características segmentales, características supra segmentales, también como características de la calidad de la voz y dimensiones físicas" (p. 233).

Otro aspecto intelectual muy relevante del proceso de aprendizaje es la metacognición, así como en la comprensión auditiva, hace referencia a la atención prestada a las estrategias de los estudiantes para utilizar conscientemente estrategias de pensamiento comunicativo. Según Vandergrift y Goh (2012) la metacognición se relaciona con el conocimiento que los alumnos tienen concerniente al proceso y el producto de su producción oral, la conciencia metacognitiva comprende tres dimensiones: 1. experiencia, 2. conocimiento metacognitivo y 3 . uso de estrategia. 
La experiencia metacognitiva se relaciona con las ideas, pensamientos o sentimientos que acompañan a la propia actividad cognitiva en relación con las metas perseguidas. El conocimiento metacognitivo es el conocimiento en general que tiene el individuo y el conocimiento en sí que se tiene sobre la producción oral. En otras palabras, el conocimiento metacognitivo incluye el conocimiento que se tiene sobre sí mismo como hablante (por ejemplo, la autoeficacia en relación con el tema), el conocimiento sobre la actividad de producción oral, su objetivo, también como los factores sociales y cognitivos que se presentan, y el conocimiento de estrategias que son probablemente eficaces para alcanzar fines comunicativos. Por último, el uso de estrategia como lo sugiere el término es el conocimiento acerca de cómo se planea, se utiliza, se reflexiona y se practican las estrategias discursivas y la comunicación para facilitar la interacción oral.

Las estrategias metacognitivas son relevantes tanto en el desarrollo de la producción oral como en el aprendizaje de lengua extranjera en general. Según Alexander (2008) los estudiantes que alcanzan sus objetivos consideran su aprendizaje y desarrollan formas para fomentarlo. El desarrollo metacognitivo se relaciona con el concepto del desarrollo de una mayor autonomía para lograr una mejor reflexión y motivación del propio aprendizaje y hacia el aprendizaje. En ese sentido, los docentes juegan un papel muy importante en el desarrollo metacognitivo, ya que deben brindar a sus estudiantes las oportunidades para pensar sobre las razones por las cuales están desarrollando sus habilidades de producción oral en general, y la manera cómo el desarrollo podría estar relacionado con el aprendizaje de la lengua extranjera. Los docentes pueden motivar a sus alumnos a que reflexionen sobre la retroalimentación que se les brinda, y como resultado, identificar aquellas áreas que necesitan mejorar y así reflexionar la forma en la que podrían llevarlas a cabo.
Ahora bien, en cuanto a la comprensión oral, los alumnos de las IE están expuestos al lenguaje hablado de una variedad de fuentes, la mayoría de las veces que tienen contacto con la lengua extranjera proviene de su docente, cuya voz representa la fuente más importante del input lingüístico. Además del docente, los estudiantes reciben input lingüístico al escuchar a sus compañeros de clase de inglés, mirar televisión o escuchar audios o música en la lengua extranjera. Como consecuencia de esta situación, Vandergrift (2011) sostiene que la comprensión oral es la habilidad de menor comprensión y la más difícil para estudiar, debido a esto, al momento de realizar una actividad de escucha los docentes deben proveer con una o más estrategias a sus estudiantes, con el propósito de comprender y aprender. Asimismo, Krashen (1981) afirma que "una de las más importantes habilidades a desarrollar en el aprendizaje de lengua extranjera es la comprensión oral" (p. 108), debido a que fomenta la interacción entre los individuos y, de la misma forma es utilizada en muchas áreas de trabajo o desarrollo personal y social, convirtiéndose en una de las habilidades imprescindibles y más útiles para poder desarrollar la competencia en una lengua extranjera; este proceso de interacción lleva a cabo la compresión y la producción oral.

Se destaca el hecho de que la enseñanza, la evaluación y la interpretación de las estrategias de la comprensión oral no están definidas en el currículo, es así como los docentes están obligados a interpretar el contenido del plan de área a su manera. Esto, a su vez, podría generar diferencias en la manera como los docentes evalúan a sus discentes. Lundahl (2012) manifiesta que la comprensión oral es una parte fundamental en la adquisición de una lengua. Los seres humanos no nacemos con la habilidad de escuchar de forma activa, es así como debemos aprender en la escuela. Por tal razón, los aprendices requieren escuchar $y$, por consiguiente, requieren aprender a escuchar. Esto supone que los profesores 
generen oportunidades para que los estudiantes practiquen la escucha de forma activa. Asimismo, Börjesson (2012) afirma que la comprensión auditiva es un proceso complejo y las condiciones que posee el individuo para su realización son diferentes. Es necesario que los docentes presten mayor atención al proceso que al resultado. Es así como, el aprendizaje de una lengua puede ser más eficiente si los estudiantes no deben estar obligados inmediatamente a producir todo el material que se les está exponiendo.

De igual manera, Martín (2012) expresa que desde un enfoque didáctico, la finalidad de la comprensión oral responde a que el alumno aprenda a entender, por ende, a saber escuchar. De esta manera, esto puede ayudar a los aprendices a tener una mayor conciencia de cómo mejorar su habilidad para escuchar y entender. Cabe señalar que, los estudiantes en colegios de secundaria de Colombia presentan dificultades para desarrollar sus habilidades de comprensión oral, debido a que en muchas ocasiones el ambiente de trabajo de idioma extranjero es muy limitado para desarrollar las cuatro habilidades del inglés, en consecuencia, se presta más atención a las habilidades de lectura y escritura, aunado a lo anterior, se maneja un enfoque pasivo y una carencia de estrate- gias didácticas de aprendizaje que fomenten la comprensión oral.

De la misma forma, solo una pequeña cantidad de docentes manejan estrategias para la comprensión oral, como consecuencia, afecta su motivación como docente. Igualmente, es importante manifestar, que no es suficiente con que los estudiantes efectúen las actividades auditivas para fortalecer esta habilidad. Es imperativo, además, implementar estrategias que los transformen de oyentes pasivos a oyentes activos. Vandergrift (1999) afirma que para entender la diferencia entre la escucha pasiva y la escucha activa, los estudiantes requieren ser instruidos en las estrategias que funcionen efectivamente; los docentes deben utilizar tiempo de sus clases para presentar, practicar y evaluar la efectividad de estas estrategias. De este modo, los aprendices que utilicen estrategias de comprensión oral antes, durante y después serán capaces de desarrollar las habilidades que les dan la posibilidad de monitorear su proceso metacognitivo. En primer lugar, los docentes deben seleccionar cuidadosamente audios cortos y describir que deben planear en cada una de sus tres fases, es decir, qué actividades deben realizar los estudiantes antes, durante y después de escuchar. La figura 2 expresa algunas estrategias útiles para potenciar la comprensión auditiva en cada una de sus tres fases.

Figura 2. Modelo de estrategias de comprensión oral propuesto por Börjesson, 2012

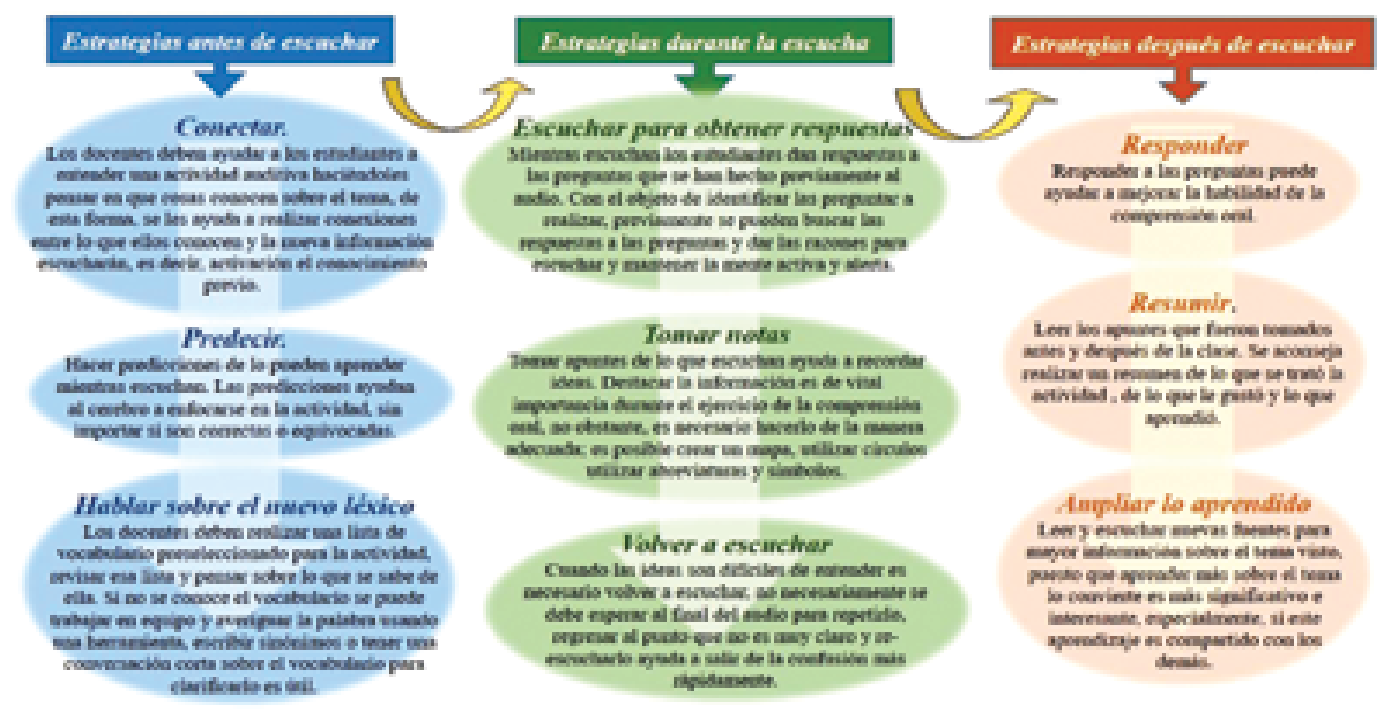




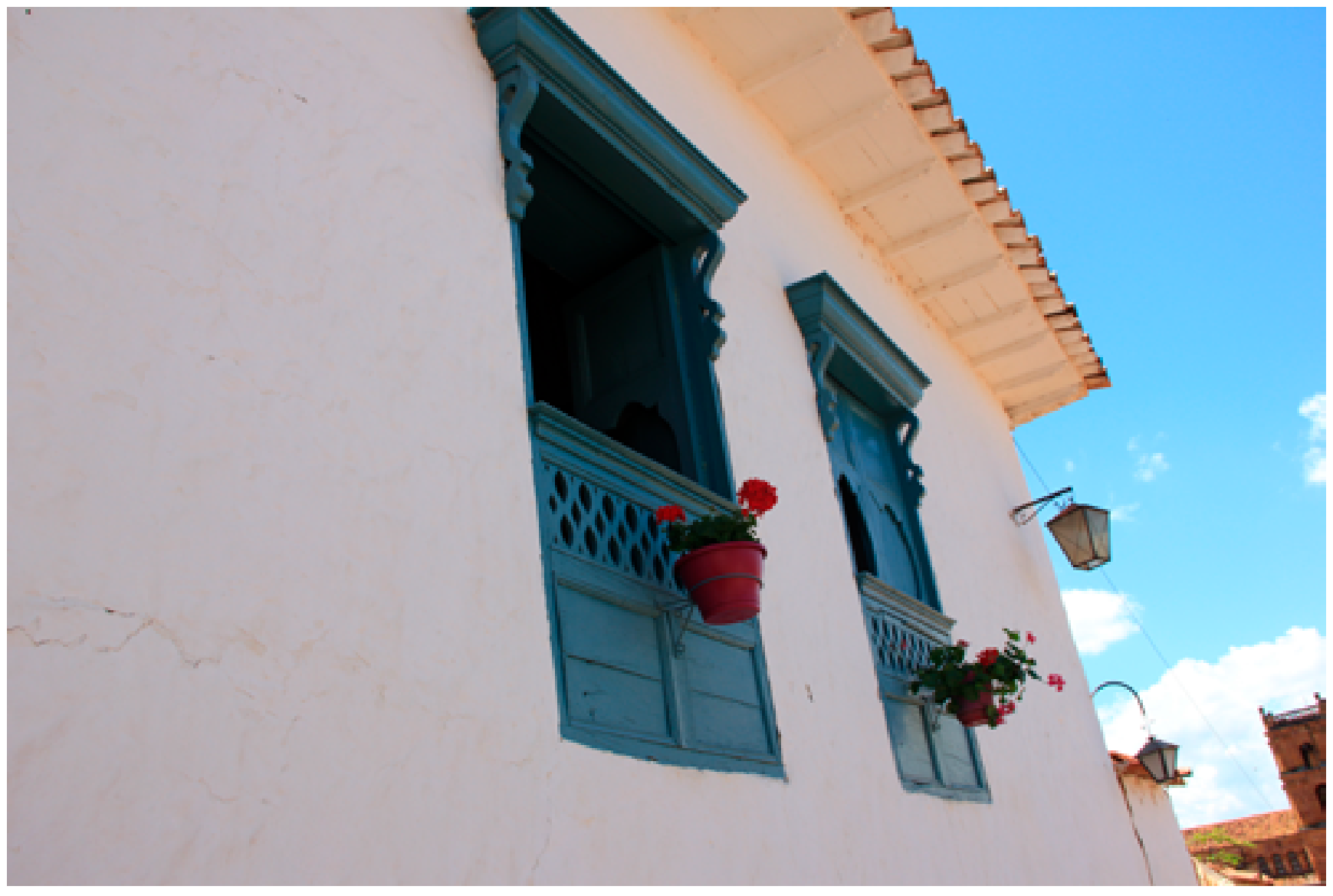

Börjesson (2012) manifiesta que si el objetivo es lograr una comprensión activa por parte de los estudiantes, es necesario tener en cuenta las estrategias metacognitivas que hacen referencia a la planeación control y evaluación de las actividades de comprensión oral, es así como ha creado un modelo de siete pasos para enseñar estas estrategias en el aula. Los siete pasos del Modelo de Börjesson son explicados a continuación:

- Primer paso: los alumnos reciben la nueva información acerca del tema y la clase de texto, crean hipótesis sobre el texto.

- Segundo, los estudiantes escuchan y verifican sus hipótesis y adhieren nueva información.

- Tercero, los estudiantes trabajan en grupos, discuten y comparan sus resultados, y llegan a un consenso.
- Cuarto, escuchan nuevamente, revisan y controlan lo entendido y lo que posiblemente aún no han logrado captar.

- Quinto, discuten nuevamente, resaltando lo más relevante y reflexionan sobre qué les hizo entender el audio y especifican palabras claves.

- Sexto, escuchan, buscan y adicionan información para verificar lo que han entendido.

- Por último, discurren acerca de lo que les ayudó a entender sugiriendo metas, tanto a nivel individual como grupal para la siguiente actividad. Este modelo incluye comprensión oral de abajo hacia arriba y de arriba hacia abajo, ya que los ejercicios de comprensión auditiva deben ofrecer una experiencia significativa para atraer la atención de los estudiantes. 
O'Malley y Chamot (1990) afirman que las estrategias de aprendizaje de la lengua se dividen en tres categorías: metacognitivas, cognitivas y socioafectivas. 1. Las estrategias metacognitivas hacen de la planeación, monitoreo y evaluación de la eficiencia una actividad de aprendizaje; 2. las estrategias cognitivas operan directamente sobre la información entrante, de tal forma que mejoran el aprendizaje; $y, 3$. las estrategias socioafectivas promueven la interacción entre los participantes para lograr el aprendizaje. En la tabla 1. Se explican a profundidad estas tres categorías, con base en Vandergrift (1997).

\section{Tabla 1. Estrategias de aprendizaje que fomentan la comprensión oral}

\begin{abstract}
(a)

\section{Planeación}

Hacen referencia a la creación de conciencia acerca de lo se debe hacer para alcanzar el logro en una actividad de comprensión auditiva, a través de un plan de acción adecuado y un plan de acción de contingencia, con el propósito de superar las dificultades que pudieran interferir con la culminación exitosa de la tarea.
\end{abstract}

\section{Estrategias metacognitivas}

\section{Monitoreo}

Corresponden a la revisión, la verificación o la corrección durante el desempeño de los estudiantes en una actividad de comprensión oral.

\section{Evaluación}

Hacen referencia a la revisión, los resultados alcanzados por los estudiantes en relación con la comprensión de lectura, en contraposición con la medida interna de exactitud y la totalidad de una actividad.

\section{Estrategias cognitivas}

\section{Inferencias}

\section{Elaboración}

Resumir

Traducción

Transferencia

Repetición

Utilizar información que está dentro del texto o el contexto conversacional para descubrir el significado del lenguaje que no es familiar en la actividad de escucha, predecir resultados o llenar información faltante.

Utilizar el conocimiento previo por parte del aprendiz y relacionarlo con el conocimiento obtenido del texto o la conversación para predecir los resultados o llenar espacios vacíos.

Realizar un resumen mental o escrito del lenguaje y la información presentada en una actividad de comprensión auditiva.

Trasladar ideas y palabras de la lengua materna a la de estudio.

Utilizar el conocimiento de una lengua para facilitar la comprensión auditiva en la lengua de estudio.

Repetir una parte del lenguaje (palabra o frase) durante el desarrollo de una actividad auditiva.

\section{Estrategias socioafectivas}

\section{Cooperación}

\section{Aclarar dudas}

Explicar, verificar, pedir ejemplos y hacer preguntas sobre la lengua o la actividad en sí.
Trabajar en equipo para resolver problemas, recolectar información con sus compañeros, revisar una actividad de aprendizaje y recibir retroalimentación sobre la actividad.

\section{Reducción de la ansiedad}

Reducir la ansiedad por medio del uso de técnicas mentales que logren que el individuo se sienta más competente para la realización de la actividad auditiva.

\section{Motivación}

Proveer motivación personal por medio de reconocimiento durante la realización o la culminación de una actividad de comprensión oral. 
Aprender implica conocer el proceso cognitivo, reconocer cómo se procesa de manera individual y cómo relacionarse asertivamente con otros, de ahí, la relevancia de las estrategias descritas y su evaluación.

\section{Metodología}

Se planteó una investigación de tipo proyectiva, orientada a mejorar el proceso de enseñanza-aprendizaje del inglés en las comunas 1 y 2 de Bucaramanga. En su fase inicial, se hizo una revisión documental sobre las estrategias didácticas desde las áreas: cognitivas, metacognitivas y socioafectivas, seguidamente, se caracterizaron los canales de percepción de los estudiantes de grado séptimo en situación de vulnerabilidad, en aras de adaptar dichas estrategias a su contexto sociocultural, posibilitando la inclusión desde el currículo y mediante la estimulación multicanales para el aprendizaje significativo.

La investigación que precede este artículo es de tipo proyectiva, orientada a mejorar el proceso de enseñanza-aprendizaje del inglés en los establecimientos de las comunas 1 y 2 de Bucaramanga que atienden estudiantes en situación de vulnerabilidad. De acuerdo con Hurtado (2000), la investigación proyectiva se basa en la creación de una propuesta o de un modelo, para resolver problemas o necesidades de carácter práctico para un grupo social, institución o un área específica del conocimiento, partiendo de un diagnóstico puntual de las necesidades del momento, los procesos explicativos o generadores involucrados y las tendencias futuras. En la fase preliminar se analizaron los planes de área de cinco IE que atienden a estudiantes en condición de vulnerabilidad de las comunas 1 y 2 del municipio de Bucaramanga, teniendo como base los lineamientos del Ministerio de Educación Nacional en su programa Colombia Bilingüe. Las instituciones participantes fueron el resultado de un muestreo por conveniencia, que aceptaron ser parte del proceso en respuesta a una solicitud formal de la Secretaría de Educación de Bucaramanga (SEB). En este sentido, Otzen y Manterola (2017) manifiestan que el muestreo por conveniencia permite la selección de casos accesibles al investigador por cercanía o aceptación de los sujetos o instituciones objeto.

Posteriormente, se caracterizaron los canales de percepción de los estudiantes de grado séptimo de la IE María Cano, mediante la aplicación del cuestionario VARK desarrollado por Fleming y Mills (1992), adaptado y validado para el contexto, a dos grupos de estudiantes de la presente IE. Este cuestionario es una propuesta para clasificar a las personas de acuerdo con su preferencia en la modalidad sensorial a la hora de procesar información o contenidos educativos. Seguidamente, a partir de los resultados de la caracterización de los planes de área de las IE participantes y los resultados del test VARK, se planteó la adaptación de las estrategias didácticas, cognitivas, metacognitivas y socioafectivas propuestas por O'Malley y Chamot (1990) al contexto sociocultural de los discentes. Con el objeto de establecer la efectividad de las estrategias mencionadas y lograr potenciar las habilidades de comprensión y producción oral, se conformaron dos grupos; Control y Experimental. La metodología utilizada en el desarrollo de las clases de L2 para el grupo Experimental empleó estrategias didácticas adaptadas para fortalecer las dos habilidades lingüísticas mencionadas, mientras que el grupo Control manejó estrategias tradicionales.

Los datos fueron procesados en el programa SPSS 19, el análisis de la dispersión de los datos en el pretest y postest se realizó por medio de los diagramas de cajas y bigotes, para validar el experimento se llevó a cabo un análisis Manova con los resultados estableciendo correlaciones con los canales de percepción caracterizados para cada uno de los estudiantes en los dos grupos y el rendimiento en las habilidades mencionadas. 


\section{Resultados}

El instrumento propuesto para la caracterización de los canales de percepción fue una adaptación del instrumento planteado por (Fleming y Mill, 1992). Se validó con un grupo de estudiantes en las mismas condiciones de quienes configuraron el Control y el Experimental, el valor de alfa de Cronbach que se obtuvo fue de 0,849 . Con lo anterior, se establece la fiabilidad del instrumento, estableciendo que los ítems miden lo que se pretende y están altamente correlacionados (George y Mallery, 2003), de acuerdo con la escala establecida por los mencionados autores está en el nivel de bueno, fue calculado haciendo uso del software SPSS 19.

El instrumento tiene como propósito, establecer el canal o los canales preferentes de percepción, definiéndolos como:

Visual (V): Preferencia por la información percibida a través de las imágenes: mapas, diagramas, figuras, fotos y dibujos.
Cenestésico (K): Preferencia perceptiva relacionada con el uso de la experiencia y la práctica.

Aural/Auditivo (A): Preferencia por la información que se escucha o se habla.

Leer/Escribir (R): Preferencia por la información mostrada a través de las palabras.

De acuerdo con las calificaciones obtenidas después de la aplicación del instrumento VARK adaptado, se establece el canal preferente de los participantes, según las puntuaciones. $\mathrm{Si}$ existen calificaciones iguales para dos o más canales de percepción, se habla de personas multimodales, es decir, tienen preferencia por dos o más canales de percepción.

Los grupos Control y Experimental quedaron caracterizados de acuerdo con lo descrito en la tabla 2.

Tabla 2. Caracterización de los canales de percepción de los grupos control y experimental

\begin{tabular}{|c|c|c|c|}
\hline Estudiantes & $\begin{array}{l}\text { Canal o } \\
\text { canales de } \\
\text { percepción }\end{array}$ & $\begin{array}{c}\text { Número de } \\
\text { estudiantes grupo } \\
\text { Control }\end{array}$ & $\begin{array}{l}\text { Número de } \\
\text { estudiantes grupo } \\
\text { Experimental }\end{array}$ \\
\hline \multirow{4}{*}{ Monomodales } & Visual & 4 & 2 \\
\hline & Cenestésico & 4 & 12 \\
\hline & Aural/auditivo & 13 & 2 \\
\hline & Leer/escribir & 7 & 3 \\
\hline \multirow{2}{*}{ Multimodales } & VA & 2 & 2 \\
\hline & RK & 2 & \\
\hline \multicolumn{2}{|c|}{ Total de estudiantes } & 32 & 21 \\
\hline
\end{tabular}

Fuente: Elaboración propia. 
Los estudiantes del grupo Control caracterizados con canal de percepción preferente visual, obtuvieron el mejor promedio en escucha en el pretest, le siguieron los estudiantes con canal preferente aural/auditivo, y en tercer lugar, se ubicaron los estudiantes con canal preferente $\mathrm{R}$, que corresponde a preferencia por la información mostrada por palabras (leer/escribir). De acuerdo con lo pormenorizado en la figura 3.

Figura 3. Evaluación habilidad auditiva por estilo de aprendizaje en grupo Control. Nota: Elaboración propia

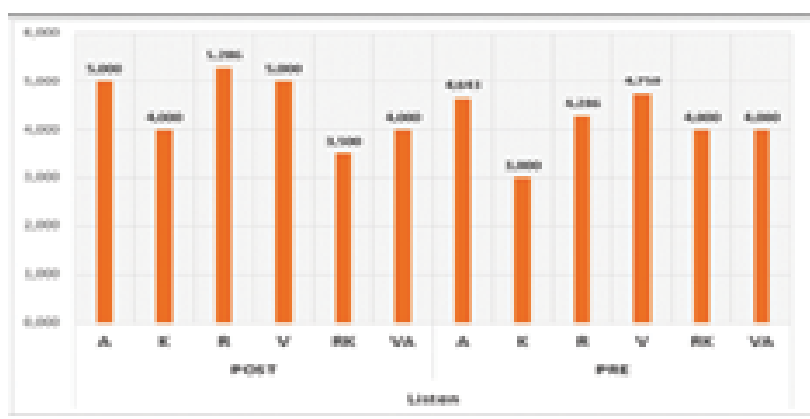

Nota: Elaboración propia

En la prueba de rendimiento denominada postest los estudiantes del grupo Control en la habilidad leer obtuvieron mejores resultados, excepto los que se ubicaron en la categoría multimodal RA que disminuyeron su promedio en 0,5 puntos y los estudiantes que se ubicaron en la categoría multimodal VA que mantuvieron un promedio de 4; los demás estudiantes y categorías obtuvieron una mejora en el puntaje que se discrimina por categoría en la tabla 3.

Tabla 3. Análisis puntajes obtenidos en pretest y postest habilidad lingüística escuchar del grupo Control

\begin{tabular}{cccc} 
Canal & $\begin{array}{c}\text { Puntaje } \\
\text { pretest }\end{array}$ & $\begin{array}{c}\text { Puntaje } \\
\text { postest }\end{array}$ & Diferencia \\
\hline A & 4,643 & 5,000 & 0,357 \\
K & 3,000 & 4,000 & 1,000 \\
R & 4,286 & 5,286 & 1,000 \\
V & 4,750 & 5,000 & 0,250 \\
RK & 4,000 & 3,500 & $-0,500$ \\
VA & 4,000 & 4,000 & 0,000 \\
& Fuente: Elaboración propia. & \\
\end{tabular}

Los estudiantes del grupo control que tienen canal de percepción preferente visual, obtuvieron el mejor promedio en la habilidad lingüística hablar en el pretest, le siguieron los estudiantes con canal preferente multicanal RK (leer-escribir/cenestésico $y$, en tercer lugar, se ubicaron los estudiantes con canal preferente A. De acuerdo con lo pormenorizado en la figura 4.

En la prueba de rendimiento denominada postest los estudiantes del grupo Control que tienen canal preferente Cenestésico son los únicos que obtuvieron mejores resultados en la habilidad hablar, de acuerdo con los descrito en la tabla 4, los otros grupos se mantuvieron como el caso de los estudiantes con canal preferente (VA) y los otros grupos tuvieron bajos resultados.

Tabla 4. Análisis puntajes obtenidos en pretest y postest habilidad lingüística hablar grupo Control

\begin{tabular}{cccc} 
Canal & $\begin{array}{c}\text { Puntaje } \\
\text { pretest }\end{array}$ & $\begin{array}{c}\text { Puntaje } \\
\text { postest }\end{array}$ & Diferencia \\
\hline A & 5,071 & 4,692 & $-0,379$ \\
K & 4,333 & 4,500 & 0,167 \\
R & 5,000 & 4,571 & $-0,429$ \\
V & 6,750 & 6,250 & $-0,500$ \\
RK & 5,500 & 5,000 & $-0,500$ \\
VA & 4,500 & 4,500 & 0,000 \\
\multicolumn{4}{c}{ Fuente: Elaboración propia. } \\
\end{tabular}

Figura 4. Evaluación habilidad hablar por estilo de aprendizaje en grupo Control.

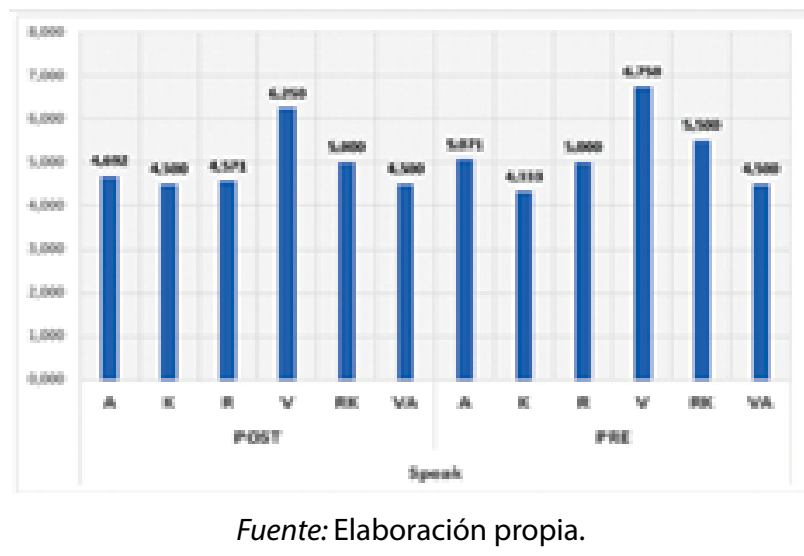


Los estudiantes caracterizados en el grupo experimental que tienen canal de percepción preferente auditivo obtuvieron el mejor promedio en escucha en el pretest, le siguieron los estudiantes con canal preferente $\mathrm{K}$ (experiencia/práctica) y, en tercer lugar, se ubicaron los estudiantes con canal preferente $V$, que corresponde a preferencia por la información mostrada por palabras imágenes. De acuerdo con lo pormenorizado en la figura 5.

Figura 5. Evaluación habilidad escuchar por estilo de aprendizaje en grupo Experimental

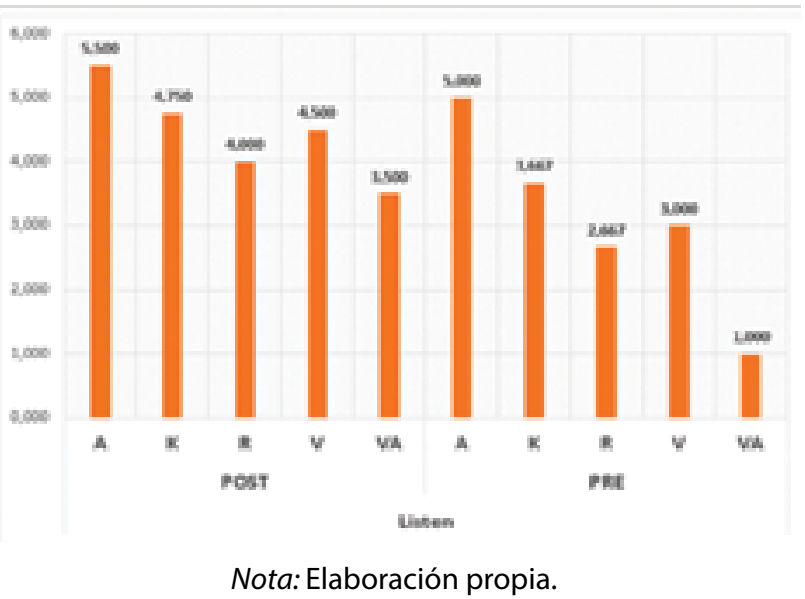

En la prueba de rendimiento denominada postest los estudiantes del grupo experimental en la habilidad escuchar obtuvieron mejores resultados en todas las categorías de acuerdo con la información registrada en la tabla 5.

Tabla 5. Análisis puntajes obtenidos en pretest y postest habilidad lingüística escuchar grupo Experimental

\begin{tabular}{crrr} 
Canal & $\begin{array}{r}\text { Puntaje } \\
\text { pretest }\end{array}$ & $\begin{array}{r}\text { Puntaje } \\
\text { postest }\end{array}$ & Diferencia \\
\hline A & 5,000 & 5,500 & 0,500 \\
K & 3,667 & 4,750 & 1,083 \\
R & 2,667 & 4,000 & 1,333 \\
V & 3,000 & 4,500 & 1,500 \\
VA & 1,000 & 3,500 & 2,500 \\
\hline
\end{tabular}

Fuente: Elaboración propia.
Los estudiantes del grupo Experimental que tienen canal de percepción preferente aura/ auditivo (A) obtuvieron el mejor promedio en la habilidad lingüística hablar en el pretest, le siguieron los estudiantes con canal preferente $\mathrm{K} y$, en tercer lugar, se ubicaron los estudiantes con canal preferente $\mathrm{R}$ y $\mathrm{V}$ con el mismo promedio. De acuerdo con lo descrito en la figura 6.

Figura 6. Evaluación habilidad hablar por estilo de aprendizaje en grupo Experimental

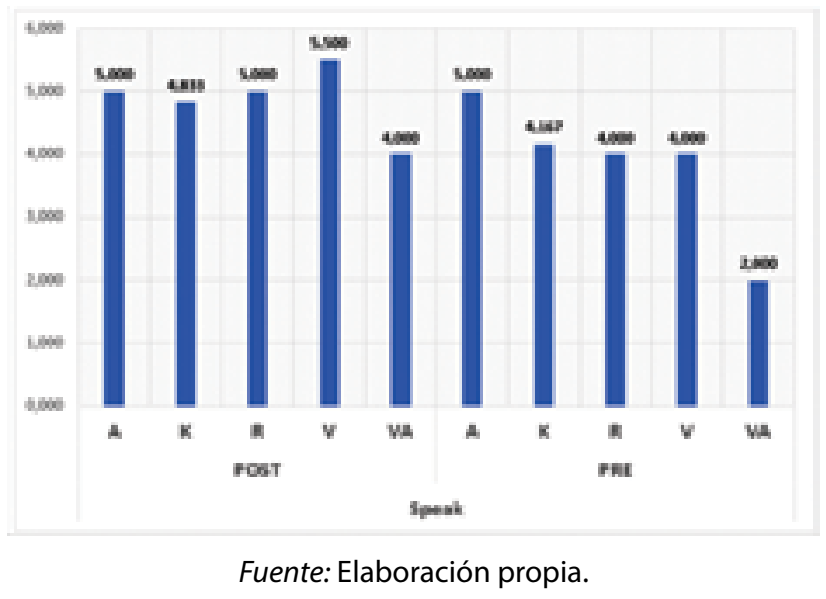

En la prueba de rendimiento denominada postest los estudiantes del grupo experimental que tienen canal preferente A (aural/auditivo) son los únicos que mantuvieron igual resultado en pretest en postest, el resto de los grupos obtuvieron mejores resultados sin superar a los del canal A, de acuerdo con la información presentada en la tabla 6.

Tabla 6. Análisis puntajes obtenidos en pretest y postest habilidad lingüística hablar

\begin{tabular}{cccc|} 
Canal & $\begin{array}{r}\text { Puntaje } \\
\text { pretest }\end{array}$ & $\begin{array}{r}\text { Puntaje } \\
\text { postest }\end{array}$ & Diferencia \\
\hline A & 5,000 & 5,000 & 0,000 \\
K & 4,167 & 4,833 & 0,666 \\
R & 4,000 & 5,000 & 1,000 \\
V & 4,000 & 5,500 & 1,500 \\
VA & 2,000 & 4,000 & 2,000 \\
\hline
\end{tabular}

Fuente: Elaboración propia. 
Para analizar la dispersión y simetría de los datos que obtuvieron los estudiantes en las pruebas pretest y postest para las habilidades escucha y habla, se implementaron los diagramas de cajas y bigotes.

En la figura 7 se analiza la simetría y dispersión de los datos obtenidos por los estudiantes del grupo control en las pruebas pretest y postest para las habilidades lingüistas comprensión auditiva y de producción oral.

Figura 7. Diagrama de cajas y bigotes para el análisis datos grupo Control en pretest y postest de las habilidades escucha y habla

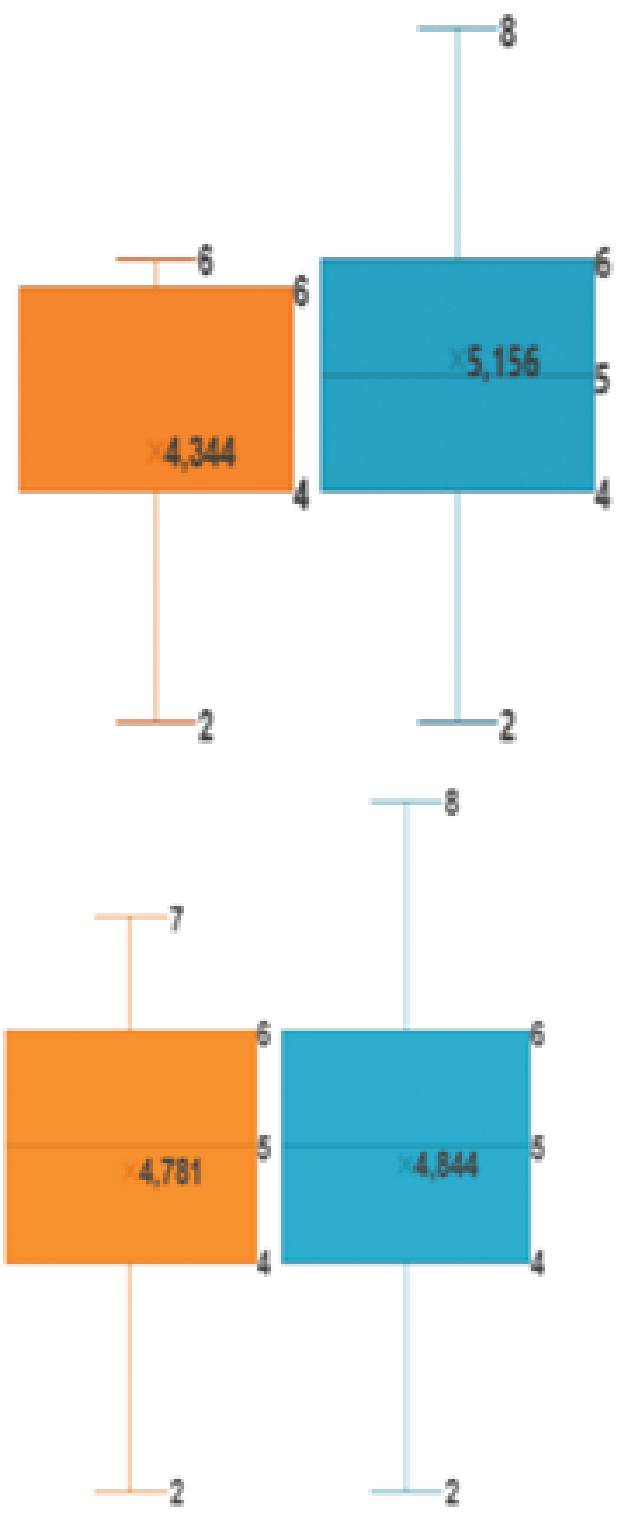

Fuente: Elaboración propia.
Los datos del pretest en lo referente a la habilidad lingüística escuchar se organizaron de la siguiente forma: el valor de Q1 fue de 4 puntos y Q3 fue de 6 puntos, el RI para esta habilidad fue de 2. Los bigotes superior e inferior son asimétricos indicando variabilidad hacia puntajes bajos. La mediana se desplazó ligeramente hacia Q1, es decir, hacia los puntajes bajos.

Los datos del postest para la misma habilidad muestran mayor dispersión entre sí, los datos se encuentran entre 2 y 7 puntos. La mediana se desplazó ligeramente hacia Q3 pasando de 4,344 en pretest a 4,781. El RI se mantuvo en 2 puntos. Los bigotes indican que $25 \%$ de los datos están entre 2 y 4 y $25 \%$ se hay dispersado ligeramente hacia los puntajes altos entre 6 y 7.

Con respecto a la habilidad lingüística hablar, los datos muestran que los puntajes en pretest estuvieron entre 2 y 8 puntos sobre los 10 puntos posibles de obtener. En pretest Q1 correspondió a 4 y Q3 fue 6 puntos. La mediana correspondió a 5,156 puntos. Los bigotes superior e inferior son simétricos (2 puntos hacia arriba y 2 puntos hacia abajo). Lo cual indica dispersión de los datos en un rango de 6 puntos.

En el postest el grupo Control obtuvo resultados entre 2 y 8 puntos la mediana se desplazó ligeramente a puntajes bajos, pasó de 5,156 puntos en pretest a 4,844 puntos. El RI se mantiene en dos puntos, lo cual muestra un retroceso en la adquisición de la habilidad.

En la figura 8 se analiza la simetría y dispersión de los datos obtenidos por los estudiantes del grupo Experimental en las pruebas pretest y postest para las habilidades lingüísticas de compresión auditiva y de producción oral. 
Figura 8. Diagrama de cajas y bigotes para el análisis datos grupo Experimental en pretest y postest de las habilidades escucha y habla

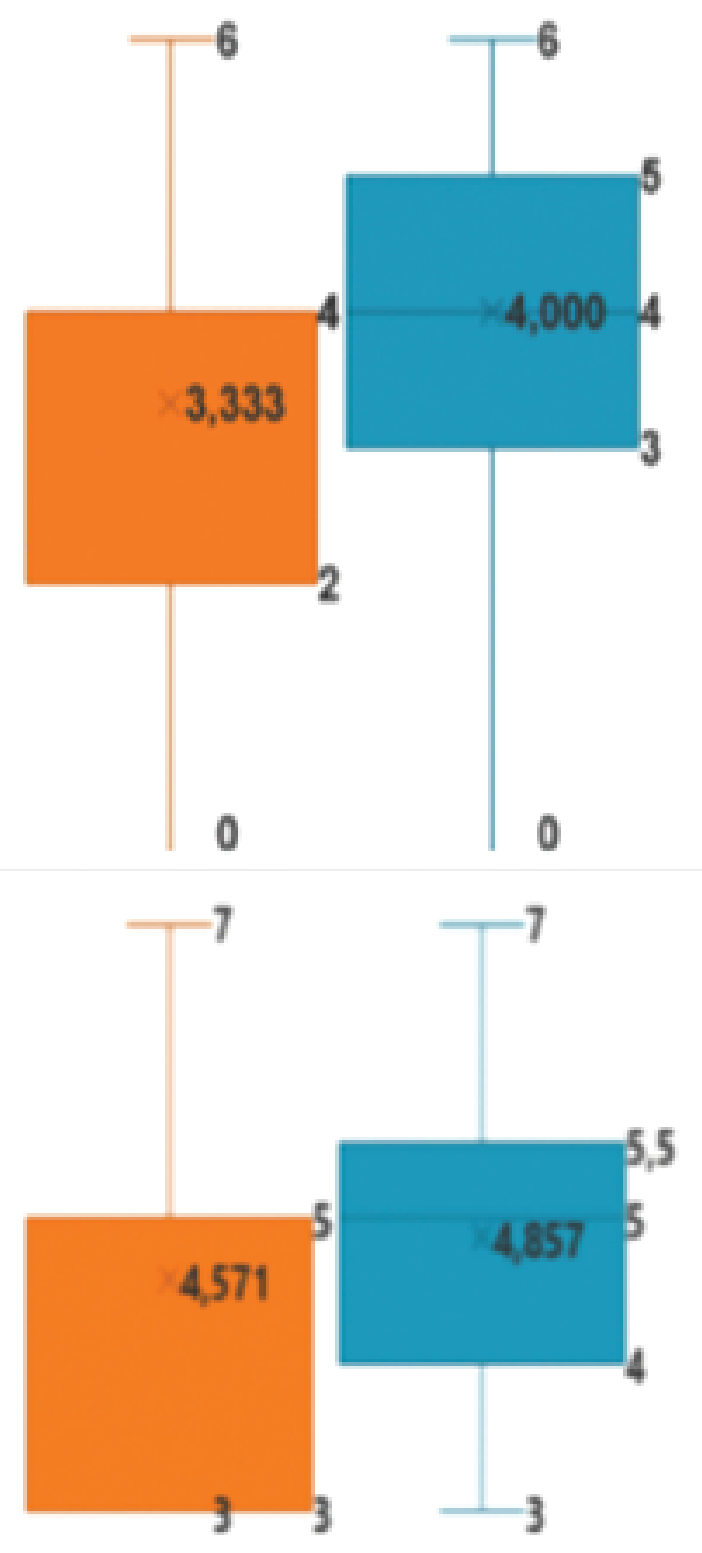

Fuente: Elaboración propia.

En la habilidad escucha se puede decir que por la forma de la caja, los datos se concentraron entre los valores 2 y 4 que correspondían al Q1 y Q3. El valor mínimo en la prueba fue de 0 puntos y el máximo de 6 . La mediana que representa el lugar central de la muestra correspondió a 3,333. De acuerdo con la longitud de los bigotes el $25 \%$ de los datos están entre 0 y 2 y otro $25 \%$ se ubica entre los puntajes 4 y 6 puntos, están simétricamente distribuidos entre los puntajes bajos y altos.
En el postest los estudiantes obtienen una mejora que se traduce en la reducción del bigote inferior que pasó de 0 a 3, el $50 \%$ de los datos se ubicaron en el rango intercuartil que va de 3 a 5 puntos. Lo anterior indica mejores resultados, el puntaje máximo pasó de 6 a 7 puntos. Los bigotes superior e inferior son asimétricos indicando variabilidad hacia puntajes altos. La mediana pasó de 3,333 a 4,571, el valor mínimo en la prueba pasó de 0 a 3.

El análisis sobre la adquisición de la habilidad hablar en el pretest indica que sí en la caja se centra el $50 \%$ de los datos estos se ubicaron entre 3 (primer cuartil, Q1) y 5 puntos (tercer cuartil, Q3). El valor máximo fue 6 puntos y el mínimo 0 puntos. Los bigotes superior e inferior son asimétricos (1 punto hacia arriba y 3 puntos hacia abajo) indicando variabilidad hacia puntajes bajos, la mediana fue de 4,000 y de acuerdo con su ubicación los datos tuvieron una distribución ligeramente asimétrica; los datos se distribuyeron en un intervalo de 0 a 6 puntos.

En postest los estudiantes del grupo Experimental en la habilidad hablar obtuvieron una mejora que se evidencia en el intervalo de los datos, que pasó de 0 a 6 a un intervalo de 3 a 7 puntos. Q1 pasó de 3 puntos a 4 puntos, Q3 pasó de 5 puntos a 5,5, lo que indica que los datos se desplazan a valores superiores. El valor mínimo en pretest fue de 0 y en postest paso a 3 puntos, el bigote inferir tenía una longitud de 3 y paso a 1, es decir, que el desplazamiento de los datos hacia valores superiores es un indicador de mejora en dicha habilidad.

Teniendo en cuenta que los resultados del grupo Control en pretest fueron superiores a los del grupo Experimental, se hace necesario el uso de covariable para establecer la incidencia de las estrategias, es decir, los dos grupos en el punto de partida con esta aplicación fueron estadísticamente iguales. En la tabla 7, se indican en rojo los tres mejores promedios por habilidad lingüística, estableciendo relaciones con el canal de percepción preferente caracterizado para el proceso. 
Tabla 7. Resultados por grupo y canal preferente

VARK aplicando covariable

\section{VARK * Grupo}

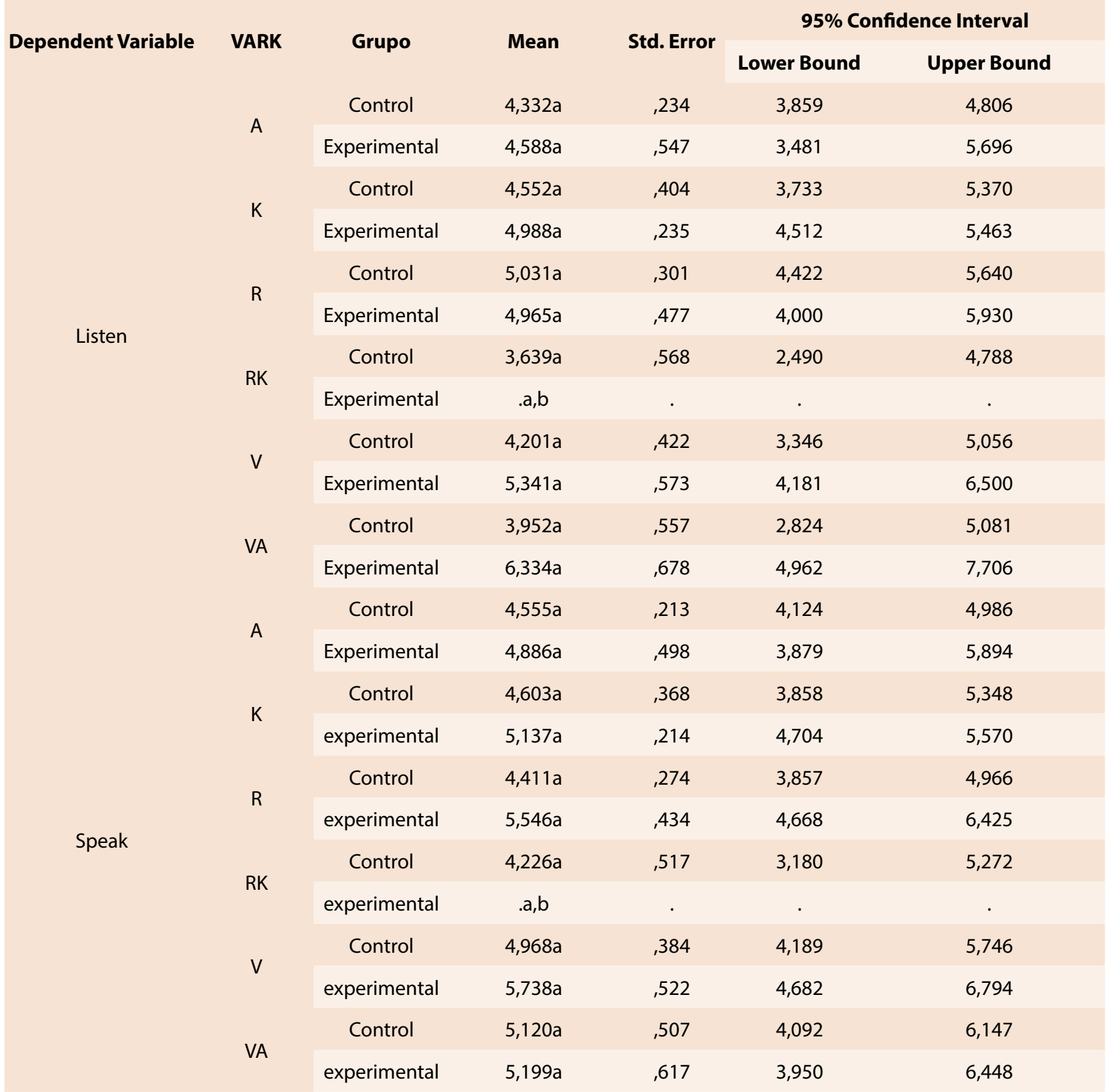

a. Covariates appearing in the model are evaluated at the following values: CovListen = 3,943 y CovSpeak = 4,698.

Fuente: Tratamiento de datos usando SPSS.

La prueba por utilizar para establecer el efecto del ambiente intencionado, en el cual se caracterizaron los canales de percepción VARK (visual, kinestésico o cenéstesico, aural o auditivo, leer, escribir) sobre la adquisición de habilidades lingüísticas en el área de inglés (comprensión auditiva y de producción oral) es la prueba de Pillai's Trace, como parte de un análisis Manova cuando se analizan dos grupos. Catena, Trujillo y Ramos (2003) concluyen que el estadístico más adecuado para el análisis de efecto y la magnitud del efecto es la traza de Pillai-Bartlett. 
Tabla 8. Test Manova para establecer efectividad del experimento

\begin{tabular}{|c|c|c|c|c|c|c|}
\hline \multicolumn{2}{|c|}{ Effect } & Value & $\mathbf{F}$ & Hypothesis df & Error df & Sig. \\
\hline \multirow{4}{*}{ Intercept } & Pillai's Trace & ,612 & $13,794 b$ & 4,000 & 35,000 & ,000 \\
\hline & Wilks' Lambda & ,388 & $13,794 b$ & 4,000 & 35,000 & ,000 \\
\hline & Hotelling's Trace & 1,576 & $13,794 b$ & 4,000 & 35,000 & ,000 \\
\hline & Roy's Largest Root & 1,576 & $13,794 b$ & 4,000 & 35,000 & ,000 \\
\hline \multirow{4}{*}{ CovListen } & Pillai's Trace & ,000 &.$b$ & ,000 & ,000 & . \\
\hline & Wilks' Lambda & 1,000 &.$b$ & ,000 & 36,500 & . \\
\hline & Hotelling's Trace & ,000 &.$b$ &, 000 & 2,000 & . \\
\hline & Roy's Largest Root & ,000 & ,000b & 4,000 & 34,000 & 1,000 \\
\hline \multirow{4}{*}{ CovSpeak } & Pillai's Trace & ,000 &.$b$ &, 000 & ,000 & . \\
\hline & Wilks' Lambda & 1,000 &.$b$ & ,000 & 36,500 & . \\
\hline & Hotelling's Trace & ,000 & .b & ,000 & 2,000 & . \\
\hline & Roy's Largest Root & ,000 &, $000 \mathrm{~b}$ & 4,000 & 34,000 & 1,000 \\
\hline \multirow{4}{*}{ CovTotal } & Pillai's Trace & ,000 & .b & ,000 & ,000 & . \\
\hline & Wilks' Lambda & 1,000 &.$b$ & ,000 & 36,500 & . \\
\hline & Hotelling's Trace & ,000 &.$b$ & , 000 & 2,000 & . \\
\hline & Roy's Largest Root & ,000 &, $000 \mathrm{~b}$ & 4,000 & 34,000 & 1,000 \\
\hline \multirow{4}{*}{ VARK } & Pillai's Trace & 439 & 937 & 20,000 & 152,000 & ,542 \\
\hline & Wilks' Lambda &, 615 & ,925 & 20,000 & 117,032 & ,557 \\
\hline & Hotelling's Trace & ,544 & 911 & 20,000 & 134,000 & ,574 \\
\hline & Roy's Largest Root & ,330 & $2,507 c$ & 5,000 & 38,000 & ,047 \\
\hline \multirow{4}{*}{ Grupo } & Pillai's Trace & 448 & $7,108 b$ & 4,000 & 35,000 & ,000 \\
\hline & Wilks' Lambda &, 552 & $7,108 b$ & 4,000 & 35,000 & ,000 \\
\hline & Hotelling's Trace & ,812 & $7,108 b$ & 4,000 & 35,000 & ,000 \\
\hline & Roy's Largest Root & ,812 & $7,108 \mathrm{~b}$ & 4,000 & 35,000 & ,000 \\
\hline \multirow{4}{*}{ VARK * Grupo } & Pillai's Trace & ,246 & ,623 & 16,000 & 152,000 & ,862 \\
\hline & Wilks' Lambda & ,763 & ,621 & 16,000 & 107,564 & 861 \\
\hline & Hotelling's Trace & ,298 & 623 & 16,000 & 134,000 & 861 \\
\hline & Roy's Largest Root & 251 & $2,382 \mathrm{c}$ & 4,000 & 38,000 & ,069 \\
\hline
\end{tabular}

Fuente: Tratamiento de datos usando SPSS. 
En la tabla 9 se presentan los resultados o efectos de las estrategias metacognitivas, cognitivas y socioafectivas adaptadas para el aprendizaje del inglés.

Tabla 9. Evaluación del efecto de las estrategias

(experimento) sobre los resultados de las habilidades lingüísticas

\begin{tabular}{|c|c|c|c|c|c|c|}
\hline \multicolumn{7}{|c|}{ Tests of Between-Subjects Effects } \\
\hline Source & Dependent Variable & $\begin{array}{c}\text { Type III Sum of } \\
\text { Squares }\end{array}$ & Df & Mean Square & $\mathbf{F}$ & Sig. \\
\hline \multirow{4}{*}{$\begin{array}{l}\text { Corrected Model } \\
\text { Intercept }\end{array}$} & Listen & $73,133 b$ & 14 & 5,224 & 9,008 & ,000 \\
\hline & Speak & $52,527 d$ & 14 & 3,752 & 7,806 & ,000 \\
\hline & Listen & 1,306 & 1 & 1,306 & 2,252 & 142 \\
\hline & Speak & 12,105 & 1 & 12,105 & 25,184 & ,000 \\
\hline \multirow{2}{*}{ CovListen } & Listen & ,000 & 0 & . & . & . \\
\hline & Speak &, 000 & 0 & . & . & . \\
\hline \multirow{2}{*}{ CovSpeak } & Listen &, 000 & 0 & . & . & . \\
\hline & Speak & ,000 & 0 & . & . & . \\
\hline \multirow{2}{*}{ CovTotal } & Listen & ,000 & 0 & . & . & . \\
\hline & Speak &, 000 & 0 & . & . & . \\
\hline \multirow{2}{*}{ VARK } & Listen & 2,226 & 5 &, 445 & ,768 & ,579 \\
\hline & Speak & 1,783 & 5 & ,357 & ,742 & ,597 \\
\hline \multirow{2}{*}{ Grupo } & Listen & 3,768 & 1 & 3,768 & 6,497 & 015 \\
\hline & Speak & 1,778 & 1 & 1,778 & 3,699 & ,062 \\
\hline \multirow{2}{*}{ VARK * Grupo } & Listen & 3,488 & 4 & 872 & 1,503 & 221 \\
\hline & Speak & ,900 & 4 & ,225 & ,468 & 759 \\
\hline \multirow{2}{*}{ Error } & Listen & 22,037 & 38 & ,580 & & \\
\hline & Speak & 18,265 & 38 & ,481 & & \\
\hline \multirow{2}{*}{ Total } & Listen & 1265,000 & 53 & & & \\
\hline & Speak & 1317,000 & 53 & & & \\
\hline \multirow{2}{*}{ Corrected Total } & Listen & 95,170 & 52 & & & \\
\hline & Speak & 70,792 & 52 & & & \\
\hline
\end{tabular}

Fuente: Tratamiento de datos usando SPSS.

Los resultados reportados fueron procesados en el software SPSS, utilizando un análisis de varianza multivariado con covarianza (las covariables utilizadas fueron los puntajes obtenidos en la prueba pretest. Se obtuvieron diferencias significativas (traza Pillai $p<0,05$ ) para la variable habilidad lingüística comprensión auditiva entre el grupo Control y el grupo Experimental, siendo superiores en este último. Hay tendencia a mostrar diferencias significativas en la habilidad lingüística producción oral. No es necesario realizar una prueba de comparación de medias, debido a que son únicamente dos tratamientos (Experimental Vs Control). 


\section{Conclusiones}

La implementación de estrategias pedagógico didácticas adaptadas para la inclusión desde el currículo tienen incidencia en la adquisición de las habilidades lingüísticas escuchar y hablar, los estudiantes del grupo Experimental lograron mejores desempeños en la prueba de la etapa de postest.

La adaptación de estrategias cognitivas, metacognitivas y socioafectivas al contexto sociocultural de los discentes de las habilidades de -escucha-listening-y producción oral-speaking- proveen a los aprendices de la lengua extranjera oportunidades de aprendizaje, a través del respeto de las particularidades de los alumnos, lo que coadyuva a que hagan uso de sus experiencias y conocimientos para generar mensajes significativos en la lengua de estudio.

Los estudiantes caracterizados con multicanal preferente VA obtienen los mejores resultados en la prueba para habilidad lingüística escucha, le siguen los estudiantes con canal preferente $\mathrm{V}$, y el tercer puesto lo obtienen los estudiantes con canal de percepción preferente R. La incidencia de los canales de percepción sobre la adquisición de las habilidades lingüísticas escucha y habla estadísticamente no es significativa.

Los estudiantes con canal preferente $\mathrm{V}$ obtienen los mejores resultados en la prueba para habilidad lingüística hablar, le siguen los estudiantes con canal preferente $R$, y el tercer puesto lo obtienen los estudiantes con canal $\mathrm{K}$. La incidencia de los canales de percepción sobre la adquisición de las habilidades lingüísticas escucha y habla estadísticamente no es significativa.

\section{Referencias}

Alexander, P. (2008). Why This and Why Now? Introduction to the Special Issue on Metacognition, Self-Regulation, and Self-Regulated Learning. Educational Psychology Review, 20, 369-372.https://doi.org/10.1007/s10648-008-9089-0
Börjesson, L. (2012). Strategier i engelska och moderna språk. Skolverket.

Burns, A., y Seidlhofer, B. (2010). Speaking and pronunciation. In N. Schmitt (ed.). An introduction to applied linguistics. (Second edition). London: Hodder Education.

Bygate, M. (1987). Speaking. Oxford University Press: CN Candlin and HG Widdowson.

Catena, A., Trujillo, H., y Ramos, M. (2003). Análisis multivariado. Un manual para investigadores. Barcelona: Biblioteca Nueva.

Chastain, K. (1998). Developing second language skills (2a. Ed.). Chicago: Harcourt Brace Publishers.

Fink, L. (2003). What is significant learning? Recuperado de https://www.wcu.edu/WebFiles/PDFs/facultycenter_ SignificantLearning.pdf

Goh, C., y Burns, A. (2012). Teaching speaking: A holistic approach. New York: Cambridge University Press.

Hedge, T. (2002). Teaching and learning in the language classroom. Oxford, UK: Oxford University Press.

Herazo, J., Jerez, S., y Lorduy, D. (2012). Opportunity and incentive for becoming bilingual in Colombia: Implications for Programa Nacional de Bilingüismo. Íkala, Revista de Lenguaje y Cultura, 17(2), 199-213. Recuperado de http://www.scielo.org.co/scielo.php?script=sci arttext\&pid=S0123-34322012000200006\&lng=en\&tlng $=$ en.

Hurtado, J. (2000). Metodología de la investigación holística. (3ra. Ed.). Caracas: Fundación Sypal.

Instituto Colombiano para la Evaluación de la Educación - ICFES. (2016). Informe nacional de resultados Saber 11 2012-2015. Recuperado de https://www.icfes.gov.co/ documents/20143/238004/Informe\%20nacional\%20 de\%20resultados\%20saber\%20pro\%202012\%20-\%20 2015.pdf

Instituto Colombiano para la Evaluación de la Educación - ICFES. (2018). Informe nacional de resultados 2014-II2017-II Saber 11. Recuperado de https://www.icfes.gov. co/documents/20143/1628232/Informe\%20nacional\%202014-2\%20al\%202017-2\%20saber\%2011\%20 -\%202018.pdf

Krashen, S. (1981). Second language acquisition and second language learning. Oxford: Oxford University Press.

Levelt, W. (1995). The ability to speak: from intentions to spoken words. European Review, 3, 13-23. https://doi. org/10.1017/S1062798700001290

López, A., Ropero, J., y Peralta, J. (2011). Estudio de validez del examen de Estado Saber 11 de inglés. Folios (34), 77-91. Recuperado de http://www. scielo.org.co/scielo.php?script=sci_arttext\&pid=S0123$48702011000200007 \&$ Ing = e n \& tIng= es

Lundahl, B. (2012). Engelsk språkdidaktik: texter, kommunikation, språkutveckling. Lund: Studentlitteratur.

Martín, S. (2012). Escuchar para entender y aprender: un reto didáctico para el profesor de ELE. Actas I Encuentro Internacional de Profesores de ELE: El aprendizaje y la enseñanza de español en contextos multiculturales y multilingües (pp. 7-17). Bruselas: Instituto Cervantes de Bruselas. 
Ministerio de Educación Nacional - MEN. (2016). Diseñando una propuesta de currículo sugerido de inglés para Colombia. Bogotá: Colombia Bilingüe. Recuperado de http:// aprende.colombiaaprende.edu.co/sites/default/files/ naspublic/Anexo\%2016\%20Dise\%C3\%B10\%20Propuesta\%20\%20Curriculo\%20Sugerido.pdf

Ministerio de Educación Nacional - MEN. (2006). Formar en lenguas extranjeras: ¡el reto! Lo que necesitamos saber y saber hacer. Serie Guías No. 22. Estándares básicos de competencias en lenguas extranjeras: Inglés Recuperado de https://redes.colombiaaprende.edu.co/ntg/men/ archivos/Referentes_Calidad/Estandares_basicos_de_ competencias/Estandares_Basicos_Competencia_en_ Lenguas_Extranjeras_\%20Ingles.pdf

Ministerio de Educación de Ecuador. (2011). Curso de inclusión educativa. Programa de formación continua del magisterio fiscal. Quito: Ministerio de Educación de Ecuador. Recuperado de https://educacion.gob. ec/wp-content/uploads/downloads/2013/03/SiProfeInclusi\%C3\%B3n-Educativa.pdf
O'Malley, J., y Chamot, A. (1990). Learning strategies in second language acquisition. Cambridge: Cambridge University Press.

Serrón, S. (2001). El enfoque comunicativo y sus implicaciones. Una visión desde la enseñanza de la lengua materna en un marco democrático. Letras, 63, 22526. Recuperado de https://dialnet.unirioja.es/servlet/ articulo?codigo $=284836$

Vandergrift, L. (1997). The Strategies of second language (French) listeners: A Descriptive Study. Foreign Language Annals, 30, 387-409. https://doi. org/10.1111/j.1944-9720.1997.tb02362.x

Vandergrift, L. (1999). Facilitating second language listening comprehension: acquiring successful strategies. English Language Teaching Jounal (ELT), 53(3), 168-76. https:// doi.org/10.1093/elt/53.3.168

Vandergrift, L. (2011). Second Language Listening: Presage, Process, Product and Pedagogy. In Hinkel, E. (Ed.). Handbook of Research in Second Language Teaching and Learning (2nd ed.). New York: Routledge.

Vandergrift, L., y Goh, C. (2012). Teaching and learning second language listening: metacognition in action. New York, NY: Routledge. 